\title{
Investigation on Laser Cladding Mechanism and Cladding Process of Iron Base Materials
}

\author{
Haibing Xiao*, Mingjun Liu and Wei Zhang \\ Intelligent manufacturing \& equipment School, Shenzhen Institute of Information Technology, Shenzhen, 518172, Guangdong, \\ China \\ ${ }^{*}$ Corresponding author
}

\begin{abstract}
In this paper, in view of laser cladding of the iron base materials, new method for laser cladding of iron-base materials were proposed. Firstly, heat transfer mechanism of the laser cladding process and metal solidification theory was studied. Second, by laser cladding test bench, laser cladding experiments process test is described, experimental researches show that 45 steel substrate cladding layer is good, laser cladding process of iron base materials can quickly obtain high density and good surface quality cladding layer.
\end{abstract}

Keywords-laser cladding; heat transfer mechanism; iron base materials; laser cladding process

\section{INTRODUCTION}

Laser cladding technology is a kind of economic benefits of high new technology, it can be on the cheap metal base material preparation of high-performance alloy surface without affecting the nature of the substrate, reduce costs, save precious rare metal materials. An alternative laser cladding technology has been studied for embedding metal-coated fiber optics into which fiber Bragg grating (FBG) sensors have been written by Tania Grandal. A three-step strategy was selected for embedding the metal coating fibers to create the best conditions to allow high-quality measurements[1].Wim Devesse presents a feedback control scheme in which a hyperspectral camera is used to provide absolute temperature measurements of the melt pool surface with a high spatial resolution of $12 \mu \mathrm{m} / \mathrm{pixel}[2]$. Microstructure and phase transformations of Fe-Ni-Cr mixed powder by laser cladding on Q235 mild steel by Tengfei Han[3]. Luo has studied a new laser cladding technique, which is based on the morphology and performance of the cladding layer [4]. The technology of power optical fiber laser as energy source, powder prepared with scraper, and rapid galvanometer laser beam scanning control districts molten metal powder in the surface of parts, achieve rapid laser cladding[4-5]. Influence on powers and process Parameters on bonding strength in laser cladding [6-9].Numerical simulation of temperature field in laser cladding of $316 \mathrm{~L}$ stainless powder on 45 steel substrate for length-direction, width-direction and helical scanning path were simulated by Ansys FEM software[10-11].Effects of Laser cladding laser parameters on Ni60A performance of cladding layer were analyzed [12].Based on this, heat transfer mechanism of laser cladding and laser cladding processing new technology were studied for iron base materials.

\section{HeAt TRANSFER MECHANISM OF LASER ClADDING}

\section{A. Heat Transfer Mechanism of Laser Cladding Model}

Laser cladding is a kind of laser surface treatment technology which refers to different ways of adding materials in the cladding coating substrate surface is selected, the laser irradiation make a thin layer of melted at the same time, the sum of the substrate surface and forming a low dilution degrees after rapid solidification, metallurgical combination of surface coating and matrix, and form a totally different from matrix composition and properties of alloy cladding layer, significantly improve the primary surface wear-resisting, corrosion resistant, heat resistance, oxidation resistance and electrical characteristics of process method, so as to achieve the surface modification or repair.

Laser cladding is a complicated process of laser melting and solidification. The small and micro yuan were set up for the heat balance on the microelement. Energy conservation function is described below:

$$
E_{\text {in }}-E_{\text {out }}=k\left[\frac{\partial(\partial T / \partial x)}{\partial x} \delta x+\frac{\partial T}{\partial x} \delta x-\frac{\partial T}{\partial x}\right] \delta y \delta z
$$

The heat conduction equation caused by convection is as follows:

$$
\rho C_{p} U x \delta z \delta y T-\rho C_{p} U x \delta z \delta y T\left(T+\frac{\alpha T}{\alpha x} \delta x\right)+\rho C_{p} U_{x} \frac{\partial T}{\partial x} \delta x \delta y \delta z=0
$$

The general equilibrium equation can be expressed as follows:

$$
k \nabla^{2} T+H_{p}=\rho C_{p}\left(U \nabla T+\frac{\partial T}{\partial t}\right)
$$

Where $E_{\text {in }}$ is reflected from the suface of the material, $E_{\text {out }}$ is the energy of through the material, $k$ is coefficient, $T$ is the temperature, $\rho$ is density, $C_{p}$ is specific heat of given pressure, $\nabla T$ is temperature, $H_{p}$ is heat per unit volume. When the wavelength is very short, the high-energy photons are more easily absorbed by a large number of delimited electrons. Considering the mass transfer caused by 
convection, the total model can be described momentum equation (4).

$$
\mu\left[\nabla^{2} \cdot v-g \beta\left(T-T_{0}\right)\right]-\rho\left[\frac{\partial V}{\partial t}+(\nabla \cdot v) v\right]=\nabla W
$$

Where $\rho$ is density, $V$ is poission's ration, $T$ is the temperature, $g$ is thickness, $\nabla W$ is laser power. Through heat transfer mechanism of laser cladding, it can be concluded that it is not only heat transfer in laser pool, but also convection and mass transfer. The flow direction of convection is related to the temperature gradient of the surface tension of the material. Laser cladding process parameters have a great influence on the dilution rate, crack, surface roughness and the compactness of cladding parts.

\section{B. Abaqus CAE for Laser Cladding}

Abaqus software which provides a variety of different method of defining the initial temperature field, can choose according to actual condition of flexible defined in different ways, thus more accurate simulation of laser cladding on the implementation of the analysis. As the most common solver, Abaqus has strong simulation function and solving ability in thermal analysis.

For the analysis of laser cladding heat conduction, the accurate definition of materials and elements is particularly important. Abaqus provides a special unit for this analysis. Defined in the material aspects of Abaqus provides the Conductivity, Specific Heat, Specific Heat, Density. On the other hand, for some special effect still can use the following material properties. Abaqus provides the Conductivity of changing with temperature and field variables, specific heat, specific heat, density modulus of elasticity, the definition of poisson's ratio and other parameters.

Laser cladding finite element model is shown in Figure I. The laser cladding model was established, and the finite element mesh was divided to simulate the laser optical path strike temperature. Model is built after the grid, in order to accurately reflect the soldering temperature gradient, when the refined mesh near the laser cladding, away from weld mesh coarsening. Convection coefficient is $10 \mathrm{~W} /\left(\mathrm{m}^{2} \cdot{ }^{\circ} \mathrm{C}\right)$ and gaussian beam is used in the heat source model.

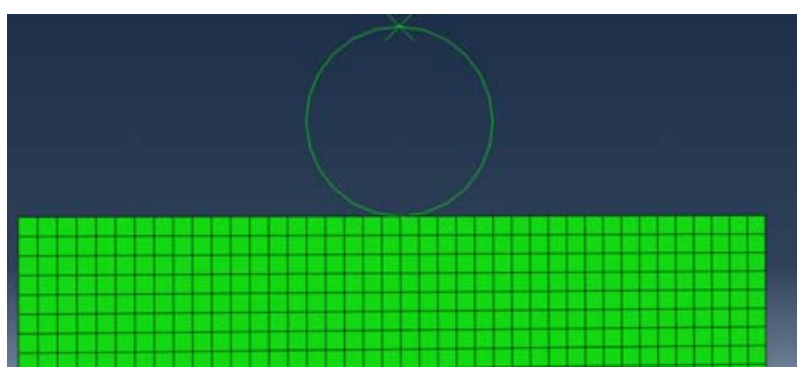

FIGURE I. LASER CLADDING FINITE ELEMENT MODEL

Temperature field variation of laser cladding is shown in Figure II. Figure II (a), (b) are laser simulation of temperature field variation of laser cladding is $1 \mathrm{~S}$, and $12 \mathrm{~S}$ respectively.

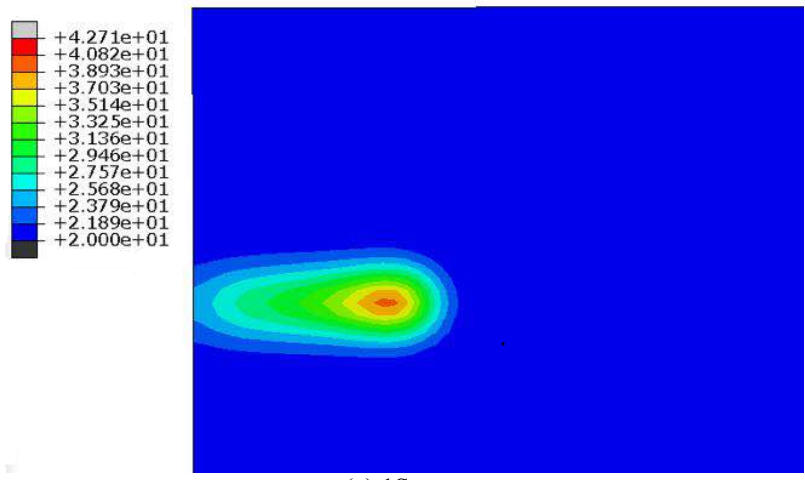

(a) $1 \mathrm{~S}$

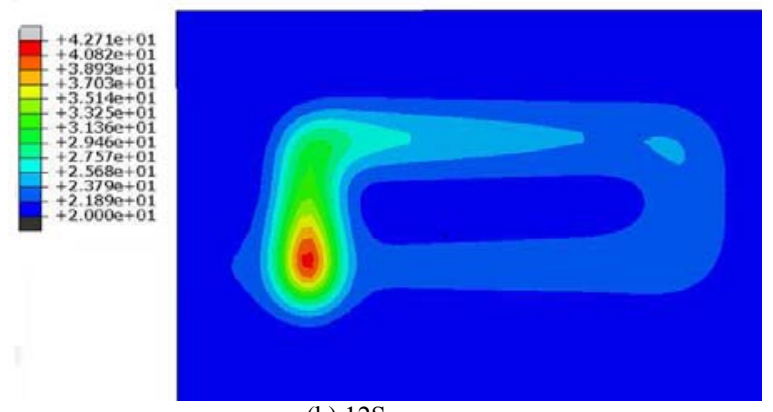

(b) $12 \mathrm{~S}$

FIGURE II. TEMPERATURE FIELD VARIATION OF LASER CLADDING (A) $1 \mathrm{~S}$, (B) $12 \mathrm{~S}$

\section{EXPERIMENT}

\section{A. Laser Cladding System}

Photograph of laser cladding system is shown in Figure III. Schematic diagram of laser cladding processing system is shown in Figure IV. Laser cladding processing system is composed of YAG laser, cooling system, feeding mechanism, computer control system, laser cladding head, laser power supply, cooling system, CNC2000 control system, working table system, z-axis lifting system, laser cladding and powder feeding system.

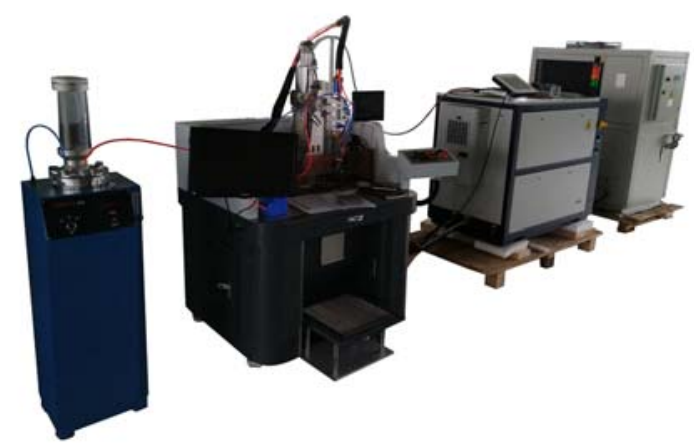

FIGURE III. PHOTOGRAPH OF LASER CLADDING SYSTEM 


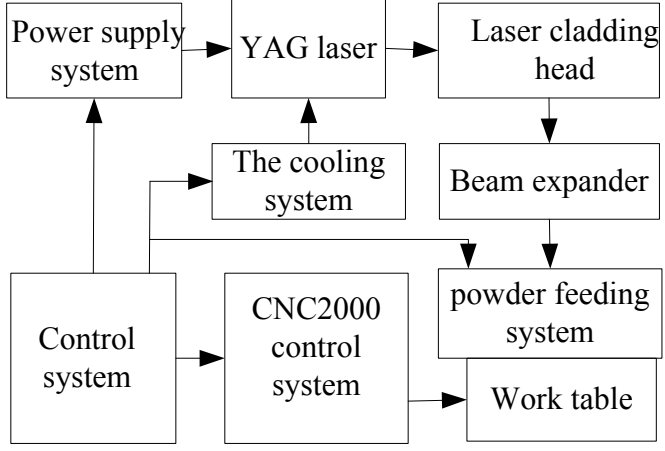

FIGURE IV. SCHEMATIC DIAGRAM OF LASER CLADDING SYSTEM

Laser cladding system laser power is $1000 \mathrm{~W}$, Laser wavelength is $1064 \mu \mathrm{m}$, the table travel is $300 \mathrm{~mm} \times 200 \mathrm{~mm}$, $\mathrm{Z}$ is from 0 to $150 \mathrm{~mm}$, pulse constant current is from $60 \mathrm{~A}$ to 600A. Laser cladding system parameters are shown in Table I.

TABLE I. LASER CLADDING SYSTEM PARAMETERS

\begin{tabular}{|c|c|c|c|}
\hline \multicolumn{2}{|c|}{ Laser Parameters } & \multicolumn{2}{c|}{ Equipment parameters } \\
\hline Laser wavelength & $1.064 \mu \mathrm{m}$ & Table travel & $\begin{array}{c}300 \mathrm{~mm} \times \\
200 \mathrm{~mm}\end{array}$ \\
\hline Laser power & $1000 \mathrm{~W}$ & $\begin{array}{c}\text { Power rated } \\
\text { maximum power }\end{array}$ & $14 \mathrm{KW}$ \\
\hline Output Mode & fiber & $\begin{array}{c}\text { Positional } \\
\text { accuracy }\end{array}$ & $0.02 \mathrm{~mm}$ \\
\hline Beam Divergence & $\leq 2.5 \mathrm{mrad}$ & Power instability & $\leq \pm 2.5 \%$ \\
\hline $\begin{array}{c}\text { Input power } \\
\text { Pulse constant } \\
\text { current }\end{array}$ & $60 \sim 600 \mathrm{~A}$ & $\begin{array}{c}\text { Automatic } \\
\text { lifting system }\end{array}$ & $150 \mathrm{~mm}$ \\
\hline
\end{tabular}

\section{B. The Flow of Laser Cladding Processing System}

The flow of laser cladding processing system is shown in Figure V. Open the control system cold water machine and click on the panel operation to start laser. The relevant operation is completed can through the button panel. After adjusting, it is necessary to release the offline key to re-enter the NC state. After the program is finished, press the program control key to enter the program control state. Improve the cladding quality and require the machining route to be set properly so as to ensure the cladding layer is even.
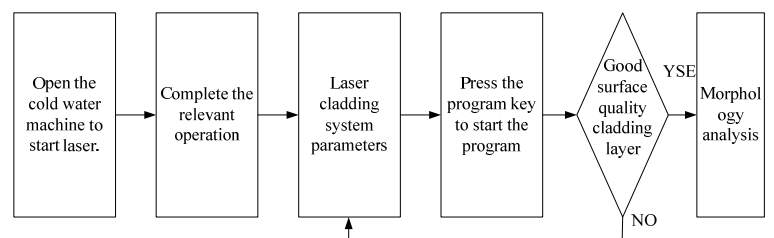

FIGURE V. THE FLOW OF LASER CLADDING SYSTEM

\section{Experiment Results}

The laser power is $600 \mathrm{~W}$, the cladding velocity is $500 \mathrm{~mm} / \mathrm{min}$; The experiment results and the processing effect of microscope graph is shown in Figure VI. Figure VI (a) is laser cladding samples, Figure VI (b) is photograph of microscopic observation under 200 times. The laser cladding parameters are not independent of the macroscopic and microcosmic quality of the cladding layer.

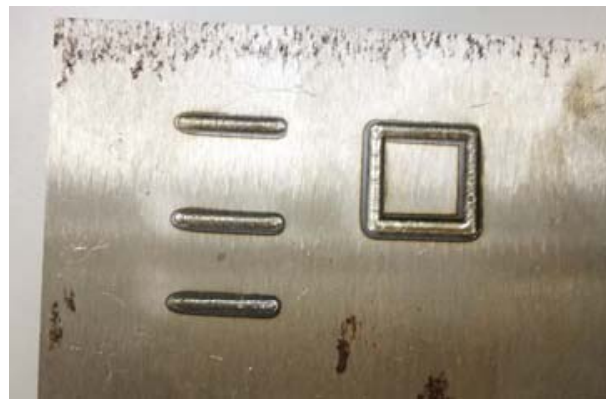

(a) Cladding samples

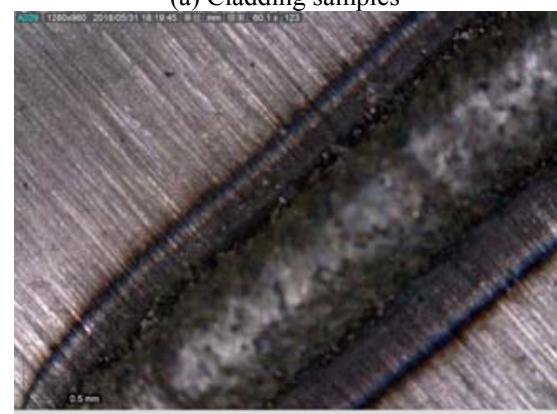

(b) Microscopic observation

FIGURE VI. THE CLADDING SAMPLES AND MICROSCOPE GRAPH

\section{CONCLUSION}

Laser cladding use high energy laser beam to melt coating material and a thin layer base metal to form a kind of good metallurgical bonding surface coating. Laser cladding process parameters have a great influence on the dilution rate, crack, surface roughness of the cladding layer and the density of the cladding parts. Each parameter also influences each other, which must be controlled by a reasonable control method within the range allowed by the laser cladding process. The laser cladding layer of 45 steel substrate is good when the process parameters are reasonable.

\section{ACKNOWLEDGEMENTS}

This work was financially supported by Shenzhen Science and Technology Plan (GJHZ20160229161749175, GGFW2017041209483817, JCYJ20170817114441260).

\section{REFERENCE}

[1] Tania Grandal, Ander Zornoza, Sergio Fraga. Laser cladding-Based Metallc Embedding Technique for Fiber optic Sensors[J].Journal of Lightwave Technology,2018,36(4):1018-1025

[2] Wim Devesse, Dieter De Baere, Michael Hinderdael, Patrick Guillaume. Model-Based Temperature Feedback control of laser cladding using high-Resolution Hyperspectral imaging[J].IEEE/ASME Transactions on Mechatronics, 2017,22(6):2714-2722.

[3] Tengfei Han, YIfu Shen,Xiaomei Feng. Microstructure and phase transformations of $\mathrm{Fe}-\mathrm{Ni}-\mathrm{Cr}$ mixed powder by laser cladding on Q235 mild steel [J].2018 15th International Bhurban Conference on Applied Sciences and Technology, 63-69.

[4] Luo Peng, Wu Weihui, Maoxing. Morphology and Performance of Laser Cladding Ni60 Coating on 45 Steel Surface Based on Galvanometer Scanning, Hot Working Technology, 2015(18):130-133(In Chinese).

[5] Weerasinghe V.M and Steen, W.M. Laser cladding by powder injection. Proc. conf. Lasers in manufacturing, Bedford, UK, ed M. KIMMITT. ifs Ltd, November 1983,pp.125-132. 
[6] Guan zhenzhong. Handbook of laser processing technology[M]. Beijing: China metrology press, 2007.

[7] $\mathrm{Yu} \mathrm{J}$, Lin X,Wang J J, et al,. Mechanics and energy analysis on molten pool spreading during laser solid forming[J].Applied Surface Science,2010,256(14):4612-4620.

[8] Song Menghua; Lin Xin; Yang Hai'ou; Huang Weidong. A Model of Constructing the End of Single-Track Laser Cladding Layer. Laser \& Optoelectronics Progress, 2015, 081408(In Chinese)

[9] Zhu Chenguang, Sun Yaoning, Yu Qing. Research State on Numerical Simulation of Temperature Field in Laser Cladding $[J]$.Hot working technology, 2012,08:132-137(In Chinese)

[10] Xu Mingsan, Liu jianfeng, Lee Hwateng, Sun Jie, Li Fangyi, Zhao Yanhua. Influence on powers and process Parameters on bonding strength in laser cladding[J].Journal of mechanical engineering, 2017,(9):209-216(In Chinese)

[11] Gong Xinyong, You Wei, Gao Shiyou, Xian Shiyu, Li Xuezhe. Numerical simulation of temperature field in laser cladding for different path[J].Journal of north china institute of science and technology, 2016, (5):48-54(In Chinese)

[12] Zhang Deqiang, Hao Yanjie, Li Jinhua. Effects of Laser cladding laser parameters on Ni60A performance of cladding layer[J].Machinery design \& manufacture, 2017,(2):115-118(In Chinese) 